\title{
Decision support for ranking Pareto optimal process designs under uncertain market conditions.
}

\author{
Laurence Tock ${ }^{\mathrm{a}, *}$, François Maréchal ${ }^{\mathrm{a}}$ \\ ${ }^{a}$ Industrial Process and Energy Systems Engineering, Ecole Polytechnique Fédérale de \\ Lausanne, Station 9, CH-1015 Lausanne, Switzerland
}

\begin{abstract}
Considering the uncertainty of economic conditions, multi-objective optimisation can be favoured to single-objective optimisation for process design. However, from the Pareto sets generated by multi-objective optimisation it is not obvious to identify the best one, given that each solution is optimal with regard to the selected objectives. A method taking into account the economic parameters uncertainty to support decision making based on the Pareto-optimal solutions is proposed. It uses a Monte-Carlo simulation to define the probability of each of the Pareto optimal configuration to be in the list of the best configurations from the economical point of view. For a given economic context defined the most probable best configurations are identified. The proposed method is applied to two cases: the $\mathrm{CO}_{2}$ capture in power plants and synthetic natural gas production from biomass resources. The results allow to identify the most attractive system designs and give recommendations for the process engineers.
\end{abstract}

Keywords: Decision making, Economic conditions, Multi-objective

\footnotetext{
*Phone: +4121693 3528 Fax: +41216933502

Email addresses: laurence.tock@epfl.ch (Laurence Tock), francois.marechal@epfl.ch (François Maréchal) 
optimization, Process design, $\mathrm{CO}_{2}$ capture, $\mathrm{SNG}$ production

\section{Nomenclature}

\section{Abbreviations}

ATR Autothermal Reforming

BM Biomass

CC Carbon Capture

CCS Carbon Capture and Storage

CFB Circulating Fluidised Bed

CFBO2 Circulating Fluidised Bed directly heated with $\mathrm{O}_{2}$

CGCL Cold Gas Cleaning

CPI Current Policy Initiatives

DH District Heating

ETS Emission Trading System

FICFB Fast Internally Circulating Fluidised Bed

pFICFB Pressurised Fast Internally Circulating Fluidised Bed

GWP Global Warming Potential

HGCL Hot Gas Cleaning

IPCC International Panel on Climate Change

LCA Life Cycle Assessment

MEA Monoethanolamine

NG Natural Gas

NGCC Natural Gas Combined Cycle

PSA Pressure Swing Adsorption

SNG Synthetic Natural Gas 
WGS Water Gas Shift

\section{Greek letters}

$\Delta h^{o} \quad$ Lower heating value, $\mathrm{kJ} / \mathrm{kg}$

$\epsilon \quad$ Energy efficiency, \%

\section{Roman letters}

$\mathrm{COE}$ Electricity production cost, $\$ / \mathrm{GJ}_{e}$

$\dot{E} \quad$ Mechanical/electrical power, $\mathrm{kW}_{e}$

$\dot{m} \quad$ Mass flowrate, $\mathrm{kg} / \mathrm{s}$

$\dot{n} \quad$ Molar flowrate, $\mathrm{kmol} / \mathrm{s}$

$\dot{Q} \quad$ Heat Flow, kW

\section{Introduction}

To meet the $\mathrm{CO}_{2}$ reduction targets and to ensure a reliable energy supply, the development and wide scale deployment of cost-competitive innovative low-carbon energy technologies is necessary. Carbon capture and storage (CCS) in power plants and the use of renewable resources for the polygeneration of biofuels, heat and power are considered as promising measures. The thermodynamic performance of different process designs depends on the process configuration (i.e. technological options and operating conditions) while the market competitiveness depends in addition on the economic conditions, especially on the resource price. Therefore, it is important to evaluate and optimise the process designs with regard to multiple competing objectives such as efficiency, investment cost and environmental impacts. Since there is a trade-off between the objectives and that the economic performance is highly influenced by the market conditions, it is difficult to identify the 
best process design from multi-objective optimisation results by taking into account the economic parameters uncertainty.

The influence of the economic conditions is frequently investigated in literature based on extreme scenarios, as in [1] for the European market and in [2] for the global market, or on sensitivity analysis. A method to support decision making based on multi-criteria decision analysis taking into account uncertainties is developed by [3]. In [4] a method for decision support in chemical process design based on the navigation on Pareto sets is proposed. The innovative slider concept [5] used to navigate on the Pareto frontiers supports decision making by choosing the best compromise between conflicting objectives. This method does not account for parameters uncertainties. Multiple decision making methods have been developed for management activities. However, the applications for process system designs are limited. To assist the multi-objective decision analysis an incentive model for primary energy savings and carbon dioxide emission reduction is presented in [6] to evaluate the Pareto operation decisions derived from a stochastic model including uncertainties. In [7] decision making and robustness strategies are combined with multi-objective optimization to optimize polymer extrusion processes.

So far systematic approaches taking into account the economic conditions fluctuation for the decision making based on the optimisation results are rarely applied and process integration aspects and life cycle assessment are not systematically assessed. Based on the systematic optimisation approach previously presented [8] and [9], a method, taking into account the economic parameter sensitivity, to support decision making based on the Pareto-optimal solutions is proposed here. The influence of the economic 
scenario on the decision-making is studied by taking into account the sensitivity of the economic performance to the carbon tax, the resource prices, the operating time, the investment and the interest rate.

\subsection{Uncertain market conditions}

The analysis of the fossil fuel market over the last years, reveals diverse patterns over time and with regard to the geographic location (i.e. Europe, the United States and Japan). This is revealed by the the energy statistics [10] and the oil and gas market data reported by the IEA [11], as well as the publications of the European Comission reporting trends [12], raw data [13] and future scenarios [14]. The large fluctuations result from multiple factors affecting the trading. In the past, the natural gas price evolution went in pair with the oil price. However, with the exploitation of shale gas this pattern changes. The coal price which is less affected by the oil price and is predicted to stabilise around $5 \$ / \mathrm{GJ}_{\text {coal }}$ in 2030 [14]. Consequently, the gas to coal price ratio is projected to increase steadily and will together with the carbon price influence investment decisions in the power sector. European gas prices are about twice as high as US gas prices and are projected to be $10 \$ / G_{N G}$ in $2020,12 \$ / \mathrm{GJ}_{N G}$ in 2030 and $16 \$ / \mathrm{GJ}_{N G}$ in 2050 for the $E U$ 'Reference' energy scenario [14]. In a similar way, the carbon tax price is influenced by multiple factors. The emission trading system (ETS) directive has been established in the European Union to promote greenhouse gas emissions reductions in a cost effective and economically efficient manner [15]. The carbon price drop from around $25 € / \mathrm{t}_{\mathrm{CO} 2}$ in 2008 to below $10 € / \mathrm{t}_{\mathrm{CO} 2}$ in the second half of 2011 because of the surplus of allowances and international credits and the financial crisis. According to the predictions from the Energy Roadmap 
2050 [14], carbon tax prices will rise moderately until 2030 and then significantly to provide support to low carbon technologies and energy efficiency. For the current policy initiatives (CPI) scenario, taking into account the latest policies on energy efficiency, taxation and infrastructure, the carbon tax is predicted to increase to $15 € / \mathrm{t}_{\mathrm{CO} 2}$ in 2020 , to $32 € / \mathrm{t}_{C O 2}$ in 2030 and to $51 € / t_{C O 2}$ in 2050 . Comparing the costs projections for different energy and policy scenarios a large variation of the predictions is found. This highlights the large uncertainty of costs projections and the need to account for different economic scenarios when evaluating the competitiveness of processes to support investment decisions.

\section{Methodology}

The applied thermo-environomic modelling and optimisation approach illustrated in Figure 1 combines flowsheeting and energy integration techniques with economic evaluation and life cycle assessment (LCA) [8] in a multi-objective optimisation framework previously presented in [16] and [9]. The main steps are summarized as following:

1. Establishment of the process superstructure and development of the process models.

2. Computation of the energy integration.

3. Assessment of the performance indicators.

4. Multi-objective optimisation.

5. Decision making.

After the assessment of candidate process technologies in a superstructure, energy-flow models are established with conventional flowsheeting soft- 
ware computing the chemical and physical transformations and the associated heat transfer requirements of each process option. The heat recovery and the combined heat and power production is optimised in the energy integration model by using the heat cascade constraints and a linear programming model minimising the operating cost [17]. The process needs are satisfied by different utilities including waste and process gas combustion, Rankine cycle, gas turbine and cogeneration. To evaluate the economic performance, the equipments are first sized and the costs are then evaluated by applying the approach and correlations reported in [18] and [19]. A multi-objective optimisation based on an evolutionary algorithm [20] is finally performed to assess the trade-offs between competing objectives and identify optimal process designs and operating conditions. Evolutionary algorithms working with populations instead of a single data point, generate multiple promising solutions in the form of a Pareto-optimal frontier. The Pareto-optimal solutions correspond to the configurations for which it is not possible to improve one objective without simultaneously downgrading one of the other objectives. It is a priori not obvious which configuration has to be chosen from the Pareto results.

Therefore, the aim is here to propose an approach which allows to identify the optimal process design from the Pareto-optimal solutions taking into account the economic conditions sensitivity.

\subsection{Decision support approach}

In this approach (Figure 1), the economic conditions fluctuation is first described by probability distribution functions (Section 2.1.1). By applying the distribution functions a series of 1000 economic scenarios is randomly 


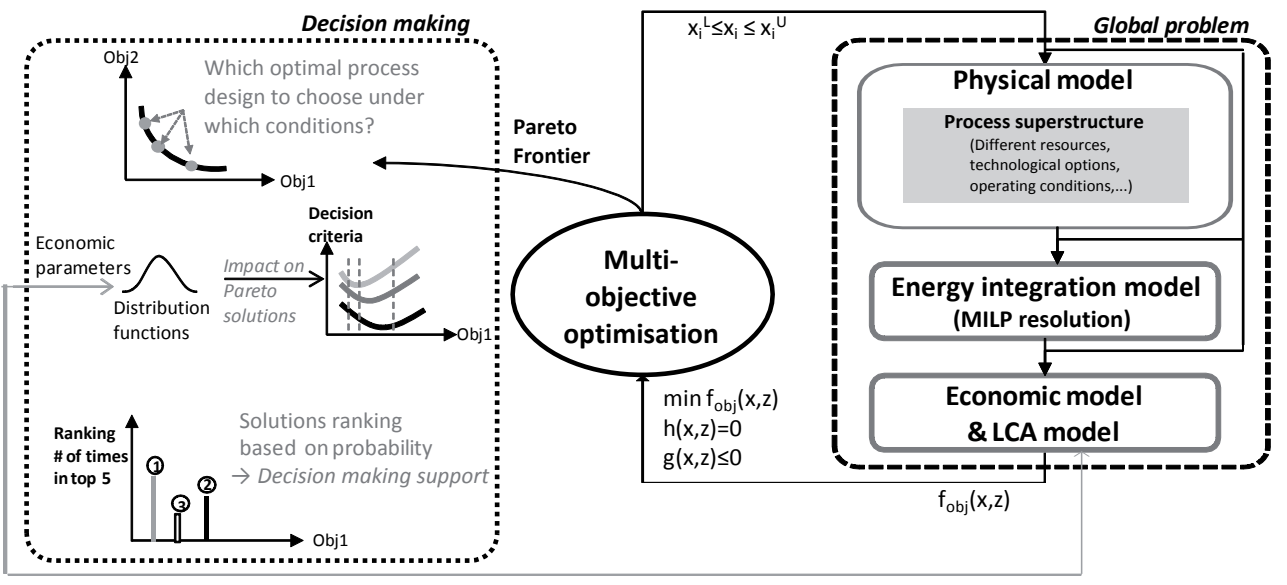

Figure 1: Thermo-environomic optimisation strategy to support decision-making.

generated. For every single economic scenario and for each configuration (i.e. process design) of the Pareto frontiers resulting from the multi-objective optimisation, the decision criterion/criteria is/are then recomputed. From the Pareto-optimal solutions the designs that yield the best performance (best, top 5 and top 10) with regard to the decision criteria are then identified for each economic scenario. After having identified the most economically competitive designs in the wide range of economic scenarios, it can be found out if some configurations are dominating or if some are never part of the best performing ones. To evaluate this quantitatively, the probability to be part of the best performing designs is assessed for each point of the Pareto front. The different process designs can then be ranked based on this probability. This allows finally to identify the most economically competitive process design in a wide range of economic scenarios.

The following steps summarise the decision support approach that allows to rank the different process designs and to identify the best process design 
taking into account the economic parameters sensitivity.

1. Generation of the Pareto frontiers by multi-objective optimisation. When several technology options can be considered, one Pareto frontier is generated per process option.

2. Definition of probability distribution functions for each uncertain economic parameter (i.e. resource price, carbon tax, interest rate,...).

3. Generation of a set of 1000 different economic scenarios based on the probability distribution functions.

4. For each economic scenario:

- Recalculation of the decision criteria (i.e. lowest production costs, highest profit, ...) for each Pareto optimal solution.

- Ranking of the process designs with regard to the decision criterion.

- Identification of the best and top 5 process designs.

5. Repeat step 3 for each economic scenario.

6. Assessment of the probability to perform the best. For each Pareto optimal solution the probability to be the best and the probability to be part of the 5 best process configurations are calculated. The best performance is evaluated based on one or several decision criteria/on, being a chosen performance indicator (i.e operating cost, profitability, ...).

7. Identification of the overall best, most robust process design. 


\subsubsection{Distribution functions - Uncertain parameters}

The economic conditions fluctuation is described by probability distribution functions. Characteristic distribution functions that are applied here are the normal, uniform and beta distributions. Different approaches are discussed in [21]. The normal or Gaussian distribution is a continuous probability distribution that has a bell-shape probability density function given by Eq.1. The parameter $\mu$ is the mean and $\sigma^{2}$ is the variance and $\sigma$ the standard deviation. The continuous uniform distribution is characterised by the lower $a$ and upper $b$ endpoint defining the distribution support. Each point in this interval is equally probable. The probability density function for $\mathrm{x} \in[a, b]$ is given by Eq.2. The beta distribution is a continuous probability distribution that is defined in the interval $[0,1]$ and is parameterised by two positive shape parameters $a$ and $b$. This distribution characterised by the probability density function Eq.3 is frequently applied to model the behaviour of random variables limited to a finite interval.

$$
\begin{aligned}
f\left(x ; \mu, \sigma^{2}\right) & =\frac{1}{\sigma \sqrt{2 \Pi}} e^{-\frac{1}{2}\left(\frac{x-\mu}{\sigma}\right)^{2}} \\
f(x) & =\frac{1}{a-b} \\
f(x ; a, b) & =c \cdot x^{a-1} \cdot(1-x)^{b-1}
\end{aligned}
$$

Based on available literature data about economic scenarios projections from IEA and the European Comission [10, 11, 14, 12, 13, 1], the lower and upper boundary values are defined for each economic parameter. The appropriate distribution function is then selected and the characteristic parameters are identified in such a way that boundary values are part of the distribution. 
The distributions for the natural gas price and the carbon tax are represented in Figure 2 and the parameters of the probability density functions are reported in Table 1. The variation of the natural gas price is represented by a normal distribution. The carbon tax price which is assumed to increase most probably in the future is described by a beta distribution function.

Table 1: Definition of the parameters of the distribution functions for the natural gas price and carbon tax. The boundary values are based on $[10,11,14,12,13,1]$

\begin{tabular}{lccccccc}
\hline & \multicolumn{3}{c}{ Scenario } & \multicolumn{5}{c}{ Distribution functions parameters } \\
& Base & Low & High & Distribution & Param. A & Param. B & Param. C \\
\hline Natural gas price $\left[\$ / \mathrm{GJ}_{N G}\right]$ & 9.7 & 5.5 & 14.2 & Normal & $\mu=9.7$ & $\sigma=2.5$ & - \\
Carbon tax $\left[\$ / \mathrm{t}_{\mathrm{CO} 2}\right]$ & 35 & 20 & 55 & Beta & $\mathrm{a}=2$ & $\mathrm{~b}=1.5$ & $\mathrm{c}=100$ \\
\hline
\end{tabular}

\section{Applications}

The previously described methodology is applied to identify under uncertain market conditions the best process designs from the multi-objective optimisation results of two different systems: a) $\mathrm{CO}_{2}$ capture in power plants and b) Synthethic natural gas (SNG), heat and power poly-generation from lignocellulosic biomass.

\section{1. $\mathrm{CO}_{2}$ capture in power plants}

For $\mathrm{CO}_{2}$ capture in power plants three major concepts are suitable: post-, pre- and oxyfuel-combustion. The thermo-economic competitiveness of these $\mathrm{CO}_{2}$ capture options depends on the power plant layout, the resources type, the capture technology and the economic conditions. The penalty of $\mathrm{CO}_{2}$ capture in terms of efficiency and costs has been evaluated by the European 

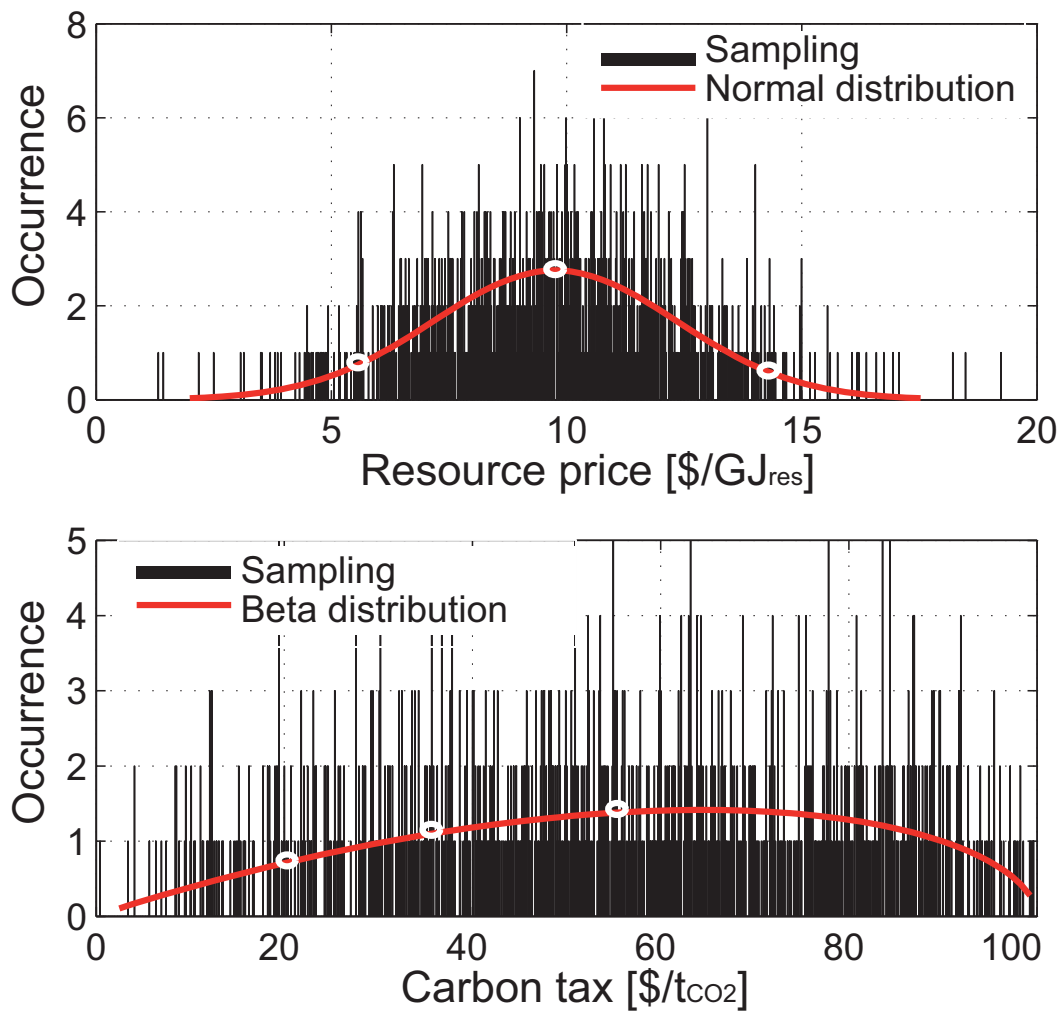

Figure 2: Distribution function (in red) of the natural gas price (top) and of the carbon tax (bottom). The white dots correspond the values reported in Table 1. The black bars represent the random sample of 1000 values.

Technology Platform [1], the International Panel on Climate Change [22] and the International Energy Agency [2]. Diverse layouts have been compared by [23] and [24]. Different process configurations based on fossil and renewable resources have been evaluated based on process modelling and simulation in [25-27] and [28] without including detailed process integration and economic considerations. An extensive life cycle assessment ( $\mathrm{LCA})$ of $\mathrm{CO}_{2}$ capture options is performed in [29], while economic and environmental aspects are combined in [30]. Nevertheless, none of these studies combines extensive flow- 
sheeting with thermodynamic, economic and environmental considerations simultaneously to make a comprehensive comparison of $\mathrm{CO}_{2}$ capture options in power plants applications. All these studies reveal that the competitiveness of $\mathrm{CO}_{2}$ capture processes on the future energy market is determined by the economic conditions, especially the resource price and the introduction of a carbon tax. The influence of the economic conditions is frequently investigated based on extreme scenarios or sensitivity analysis $[1,31]$, however no systematic approach taking into account the economic conditions fluctuation for the decision making based on the optimisation results is applied.

The decision support approach is applied here to identify the best $\mathrm{CO}_{2}$ capture process design under uncertain market conditions.

\subsection{1. $\mathrm{CO}_{2}$ capture process description}

Three representative $\mathrm{CO}_{2}$ capture options, illustrated in Figure 3, are investigated: 1) Post-combustion $\mathrm{CO}_{2}$ capture by chemical absorption with monoethanolamine (MEA) applied to a natural gas combined cycle (NGCC) plant $\left(582 \mathrm{MW}_{t h, N G}\right)$. This option, abbreviated hereafter as $N G$ post-, is the same as the one described in [32]. 2) Pre-combustion $\mathrm{CO}_{2}$ capture by physical absorption with Selexol in a natural gas fueled power plant (725 $\mathrm{MW}_{t h, N G}$ ) based on autothermal reforming. This option, referred to hereafter as NG pre-,has been described and analysed previously in [33] and [34] for $\mathrm{H}_{2}$ production applications. 3) Pre-combustion $\mathrm{CO}_{2}$ capture by physical absorption with Selexol in a biomass fired power plant $\left(380 \mathrm{MW}_{t h, B M}\right)$ based on fast internally circulating fluidised bed gasification. The biomass resource is wood characterised by a weight composition of $51.09 \% \mathrm{C}, 5.75 \% \mathrm{H}, 42.97 \% \mathrm{O}$ and $0.19 \% \mathrm{~N}$, and a humidity of $50 \%$ wt. This option, labeled hereafter as 
BM pre-, has been described and analysed previously in [35]. For all the cases $\mathrm{CO}_{2}$ compression to 110 bar for subsequent transport and storage is included to evaluate the thermo-environomic performance. The key operating parameters of the investigated pre- and post-combustion processes are reported in Tables 2 and 3.



Figure 3: Investigated $\mathrm{CO}_{2}$ capture processes for electricity production.

A multi-objective optimisation is performed with the objective of maximising the energy efficiency (Eq.4) and the $\mathrm{CO}_{2}$ capture rate (Eq.5) with regard to the process operating parameters (i.e. reforming, gasification and water gas shift temperature and pressure, steam to carbon ratio, capture unit design, absorption and desorption operating conditions, cogeneration system configuration,... (Tables 2 and 3).

The energy efficiency $\epsilon_{\text {tot }}$ is defined by the ratio between the net electricity output $\left(\Delta E^{-}=\dot{E}^{-}-\dot{E}^{+}\right)$and the resources energy input, expressed on the basis of the lower heating value $\left(\Delta h^{0}\right)$, according to Eq.4.

$$
\epsilon_{t o t}=\frac{\Delta E^{-}}{\Delta h_{N G, i n}^{0} \cdot \dot{m}_{N G, i n}}
$$


Table 2: Decision variables for the post-combustion $\mathrm{CO}_{2}$ capture process using chemical absorption process with monoethanolamine.

\begin{tabular}{lc}
\hline Operating parameter & Range \\
\hline FGR $[-]$ & {$[0-0.56]$} \\
Lean solvent $\mathrm{CO}_{2}$ loading $[\mathrm{kmol} / \mathrm{kmol}]$ & {$[0.18-0.25]$} \\
Rich solvent $\mathrm{CO}_{2}$ loading $[\mathrm{kmol} / \mathrm{kmol}]$ & {$[0.4-0.5]$} \\
Rich solvent pre-heat T $\left[{ }^{\circ} \mathrm{C}\right]$ & {$[95-105]$} \\
Rich solvent re-heat T $\left[{ }^{\circ} \mathrm{C}\right]$ & {$[115-125]$} \\
LP stripper pressure $[\mathrm{bar}]$ & {$[1.7-2.1]$} \\
HP / LP pressure ratio $[-]$ & {$[1-1.5]$} \\
MEA \% in solvent $[-]$ & {$[0.3-0.35]$} \\
Absorber steam out $\left[\mathrm{kg}_{H}{ }^{2 O} / \mathrm{t}_{F G}\right]$ & {$[306-309.5]$} \\
Split fraction $[-]$ & {$[0-0.7]$} \\
Nb stages absorber & {$[10-17]$} \\
Nb stages HP stripper & {$[8-15]$} \\
Nb stages LP stripper & {$[6-10]$} \\
Absorber diameter $[\mathrm{m}]$ & {$[6-12]$} \\
HP stripper diameter $[\mathrm{m}]$ & {$[3-6]$} \\
LP stripper diameter $[\mathrm{m}]$ & {$[2-5]$} \\
\hline
\end{tabular}

$$
\eta_{C O 2}=\frac{\dot{n}_{C_{\text {captured }}}}{\dot{n}_{C_{\text {in }}}} \cdot 100
$$

To evaluate the economic performance the electricity production costs, including the annual capital investment and the operation and maintenance costs, are computed. The capital investment of each equipment assessed based on cost correlations reported in [18] and [19] is update to year 2014 with the Marshall and Swift cost index accounting for inflation. The total capital investment is annualised taking into account the interest rate and the plant lifetime. The maintenance costs are assumed to be 5\% of the initial annual investment. The operating costs mainly consist of the purchase of the resources, which are here the natural gas and biomass feedstock.

The competitiveness of the $\mathrm{CO}_{2}$ capture options is compared with a conventional NGCC plant $\left(559 \mathrm{MW}_{t h, N G}\right)$ without $\mathrm{CO}_{2}$ capture characterized by an efficiency of $58.7 \%$, specific $\mathrm{CO}_{2}$ emissions of $105 \mathrm{~kg}_{\mathrm{CO} 2} / \mathrm{GJ}_{e}$, COE of 
Table 3: Decision variables for the pre-combustion $\mathrm{CO}_{2}$ capture (physical absorption with Selexol solvent) processes using natural gas or biomass as a feedstock.

\begin{tabular}{llr}
\hline Section & Specification & Range \\
\hline Biomass drying & $\mathrm{T}[\mathrm{K}]$ & 473 \\
Biomass pyrolysis & $\mathrm{T}[\mathrm{K}]$ & 533 \\
Biomass gasification & $\theta_{\text {wood,gasif_in }}[\% \mathrm{wt}]$ & {$[5-35]$} \\
& $\mathrm{T}[\mathrm{K}]$ & {$[1000-1200]$} \\
& $\mathrm{P}[\mathrm{bar}]$ & {$[1-15]$} \\
SMR after gasification & $\mathrm{T}[\mathrm{K}]$ & {$[950-1200]$} \\
ATR & $\mathrm{T}[\mathrm{K}]$ & {$[780-1400]$} \\
& $\mathrm{P}[\mathrm{bar}]$ & {$[1-30]$} \\
& $\mathrm{S} / \mathrm{C}[-]$ & {$[0.5-6]$} \\
WGS & $\mathrm{T}_{H T S}(\mathrm{NG} / \mathrm{BM})[\mathrm{K}]$ & {$[523-683] /[573-683]$} \\
& $\mathrm{T}_{\text {LTS }}(\mathrm{NG} / \mathrm{BM})[\mathrm{K}]$ & {$[423-523] /[423-573]$} \\
& $\mathrm{P}(\mathrm{BM})[\mathrm{bar}]$ & {$[1-25]$} \\
& $\mathrm{S} / \mathrm{C}(\mathrm{BM})[-]$ & {$[0.2-4]$} \\
$\mathrm{CO}_{2}$ capture & Selexol/CO ${ }_{2}$ ratio $[\mathrm{kg} / \mathrm{kg}]$ & {$[8-14]$} \\
& Absorber T $\left[{ }^{\circ} C\right]$ & {$[-18-173]$} \\
& Absorber P $[$ bar $]$ & {$[10-60]$} \\
& Nb stages absorber & 10 \\
& Absorber packing & Pall ring \\
& Regeneration P [bar] & {$[1-10]$} \\
& Regeneration T $\left[{ }^{\circ} C\right]$ & {$[25-100]$} \\
\hline
\end{tabular}

$18.3 \$ / \mathrm{GJ}_{e}$ without carbon tax.

The multi-objective optimisation results illustrated in Figure 4 reveal the trade-off between the energy efficiency and the $\mathrm{CO}_{2}$ capture rate. An increase of the $\mathrm{CO}_{2}$ capture rate leads to a decrease of the energy efficiency due to the energy consumption for $\mathrm{CO}_{2}$ capture and compression to 110 bar. Considering only these two performance indicators no evident decision in favor of one specific process configuration can be made. To evaluate the process market competitiveness, the economic dimension has to be included. $\mathrm{CO}_{2}$ capture induces additional investment costs for the capture equipment (i.e. absorber and desorber) and the $\mathrm{CO}_{2}$ compressor. Together with the 


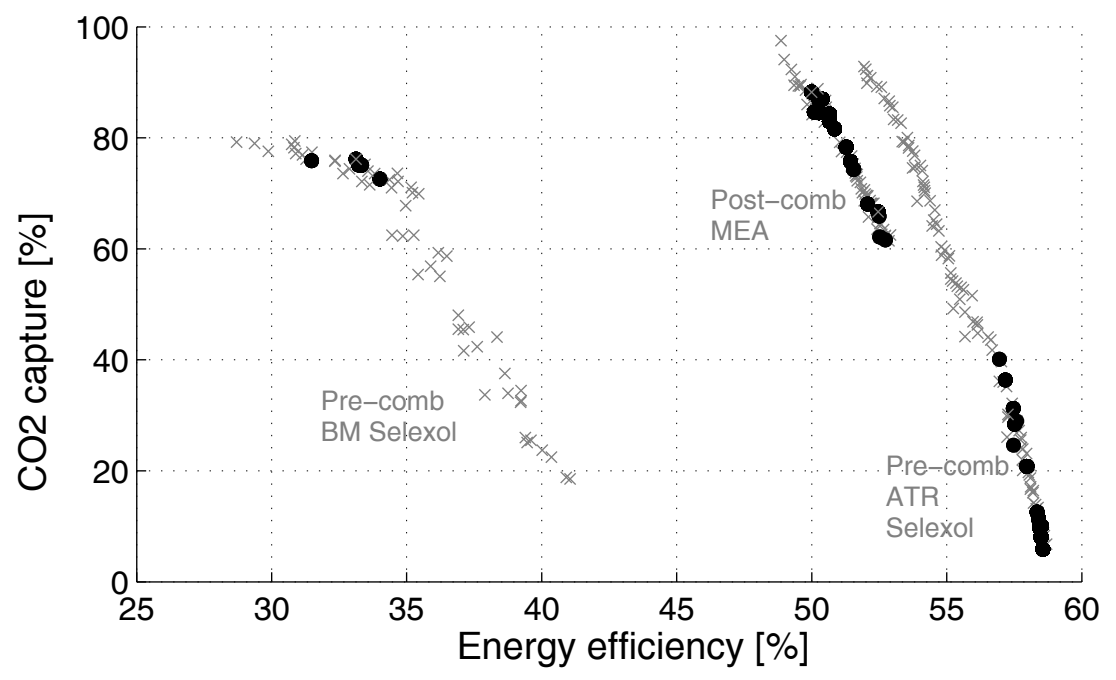

Figure 4: Power plants performance with $\mathrm{CO}_{2}$ capture: Decision-making based on the Pareto front (black points).

reduced electricity production, this increase of the investment leads to an increase of the electricity production costs. When a carbon tax is introduced the cost penalty of $\mathrm{CO}_{2}$ capture is reduced by the benefit from the tax compared to a plant without $\mathrm{CO}_{2}$ capture inducing larger emissions. Consequently, there are break even economic conditions for which $\mathrm{CO}_{2}$ capture becomes beneficial. To take into account the economic conditions uncertainty for the decision making, the fluctuation of the different economic parameters is described by the distribution functions following the approach described in Section 2.1.1. The distribution functions are summarized in Table 4. The boundary values used to set up the distribution functions of the resource price and the carbon tax are based on [10, 11, 14, 12, 13, 1]. The yearly operation is characterised by a beta distribution as the as target of the plant is to operate closely to its design value which was here $8600 \mathrm{~h} / \mathrm{y}$. Most plants tending 
to operate for more than 10 years and operating likelihood between 20 and 30 years, a beta distribution is used to reflect the variation of the economic lifetime. The interest rate being affected by the market and the trading a normal distribution around the usual rate of $6 \%$ is used. For the investment cost estimation a presicion of $\pm 30 \%$ is reported in [18], which is reflected by the uniform distribution. For ranking the different solutions the chosen decision criteria is the electricity production costs (COE) including a carbon $\operatorname{tax}$.

Table 4: Definition of the economic scenarios and parameters of the distribution functions for the economic assumptions. The distribution functions are set up based on values from $[10,11,14,12,13,1]$

\begin{tabular}{lcccc}
\hline & \multicolumn{4}{c}{ Distribution functions parameters } \\
& Distribution & Param. A & Param. B & Param. C \\
\hline Resource price $\left[\$ / \mathrm{GJ}_{N G}\right]$ & Normal & $\mu=9.7$ & $\sigma=2.5$ & - \\
Carbon tax $\left[\$ / \mathrm{t}_{C O 2}\right]$ & Beta & $\mathrm{a}=2$ & $\mathrm{~b}=1.5$ & $\mathrm{c}=100$ \\
Yearly operation $[\mathrm{h} / \mathrm{y}]$ & Beta & $\mathrm{a}=3.9$ & $\mathrm{~b}=1.2$ & $\mathrm{c}=8600$ \\
Economic lifetime $[\mathrm{y}]$ & Beta & $\mathrm{a}=5.8$ & $\mathrm{~b}=4$ & $\mathrm{c}=40$ \\
Interest rate $[\%]$ & Normal & $\mu=0.06$ & $\sigma=0.01$ & - \\
Investment cost $[\%]$ & Uniform & $\mathrm{a}=-0.3$ & $\mathrm{~b}=0.3$ & - \\
\hline
\end{tabular}

\subsubsection{Decision making based on the Pareto-optimal solutions}

The variation of the economic performance of the Pareto optimal solutions with the economic conditions is illustrated in Figure 5.

The configurations yielding the best economic performance are identified in Figures 5\&4. Figure 4 illustrates by the black dots how the decisionmaking along the Pareto-optimal frontier changes. Figure 5 reports the variation of the $\mathrm{COE}$ of the most economically competitive configurations identified from the Pareto-optimal solutions between the upper and lower 
borderline. The economic conditions corresponding to the lower and upper boundary are respectively: 5042/7260h/y operation, $7.29 / 62.3 \$ / \mathrm{GJ}_{\text {res }}$ resource price, $89 / 55.8 \$ / \mathrm{t}_{\mathrm{CO} 2}$ carbon tax, $6.3 / 4.1 \%$ interest rate, $25.5 / 20 \mathrm{y}$ lifetime and $-23 /+25 \%$ investment costs estimation. For the base case economic scenario biomass fed processes are not competitive and post-combustion $\mathrm{CO}_{2}$ capture performs best for capture rates around 70-85\%. When gas prices increase, the natural gas based processes become uncompetitive compared to the base case biomass configurations. These results point out the competition between the processes and the influence of the economic scenario on the decision-making. This competition is highlighted in Figure 6 evaluating the overall competitiveness of each Pareto-optimal solution compared to the most-economically competitive solution. The post-combustion process configuration capturing $83 \%$ of the $\mathrm{CO}_{2}$ emissions yields a relative competitiveness of 1 since this solution is the most economically competitive one in the large range of economic conditions. These results clearly show the close competition between post- and pre-combustion and underline that the $\mathrm{CO}_{2}$ capture rate is a key factor defining the economic performance. Precombustion $\mathrm{CO}_{2}$ capture configurations, being slightly more expensive for similar capture rates, yield however slightly better efficiencies. Depending on the production scope, this could affect decision-making for the more expensive solution. For some marginal economic scenarios $\mathrm{CO}_{2}$ capture in biomass fed power plants becomes a competitive alternative. In fact, the benefit from the carbon tax overweights the efficiency penalty for capture rates around $70 \%$. The performance results of the most economically competitive process configurations are compared with the conventional NGCC 
plant without $\mathrm{CO}_{2}$ capture and summarised in Table 5. These results show how the most economically competitive process configurations can be identified from the Pareto-optimal solutions by applying the selection approach taking into account the economic conditions fluctuation.

Table 5: Process performance.

\begin{tabular}{lcccc}
\hline System & NGCC & Post-comb & ATR & BM \\
& no CC & MEA & Selexol & Selexol \\
\hline Feed $\left[\mathrm{MW}_{t h, N G / B M}\right]$ & 559 & 582 & 725 & 380 \\
$\mathrm{CO}_{2}$ capture $[\%]$ & 0 & 82.98 & 78.63 & 69.93 \\
$\epsilon_{\text {tot }}[\%]$ & 58.75 & 50.65 & 53.59 & 35.45 \\
\hline \multicolumn{5}{c}{ Base case economic scenario } \\
\hline $\mathrm{COE}$ no tax $\left[\$ / \mathrm{GJ}_{e}\right]$ & 18.31 & 22.7 & 23.7 & 46.1 \\
$\mathrm{COE}$ incl. $\operatorname{tax}\left[\$ / \mathrm{GJ}_{e}\right]$ & 22 & 23.2 & 24.5 & 21.1 \\
\hline & \multicolumn{5}{c}{ Economic scenario variation } \\
\hline $\mathrm{COE}$ incl. $\operatorname{tax}\left[\$ / \mathrm{GJ}_{e}\right]$ & $18.3-28.8$ & $9-40$ & $12.8-42$ & $15-69$ \\
\hline & Environmental Performance $(\mathrm{FU}=1 \mathrm{GJ}$ & \\
\hline $\mathrm{CO}_{2}$ emit. $\left[\mathrm{kg}_{\mathrm{CO} 2} / \mathrm{GJ}_{e}\right]$ & 105 & 13.9 & 22.2 & -198.1 \\
$\mathrm{IPCC} \mathrm{GWP}\left[\mathrm{kg}_{\mathrm{CO} 2, e q} / \mathrm{GJ}_{e}\right]$ & 120 & 35.4 & 42.2 & -167 \\
\hline
\end{tabular}



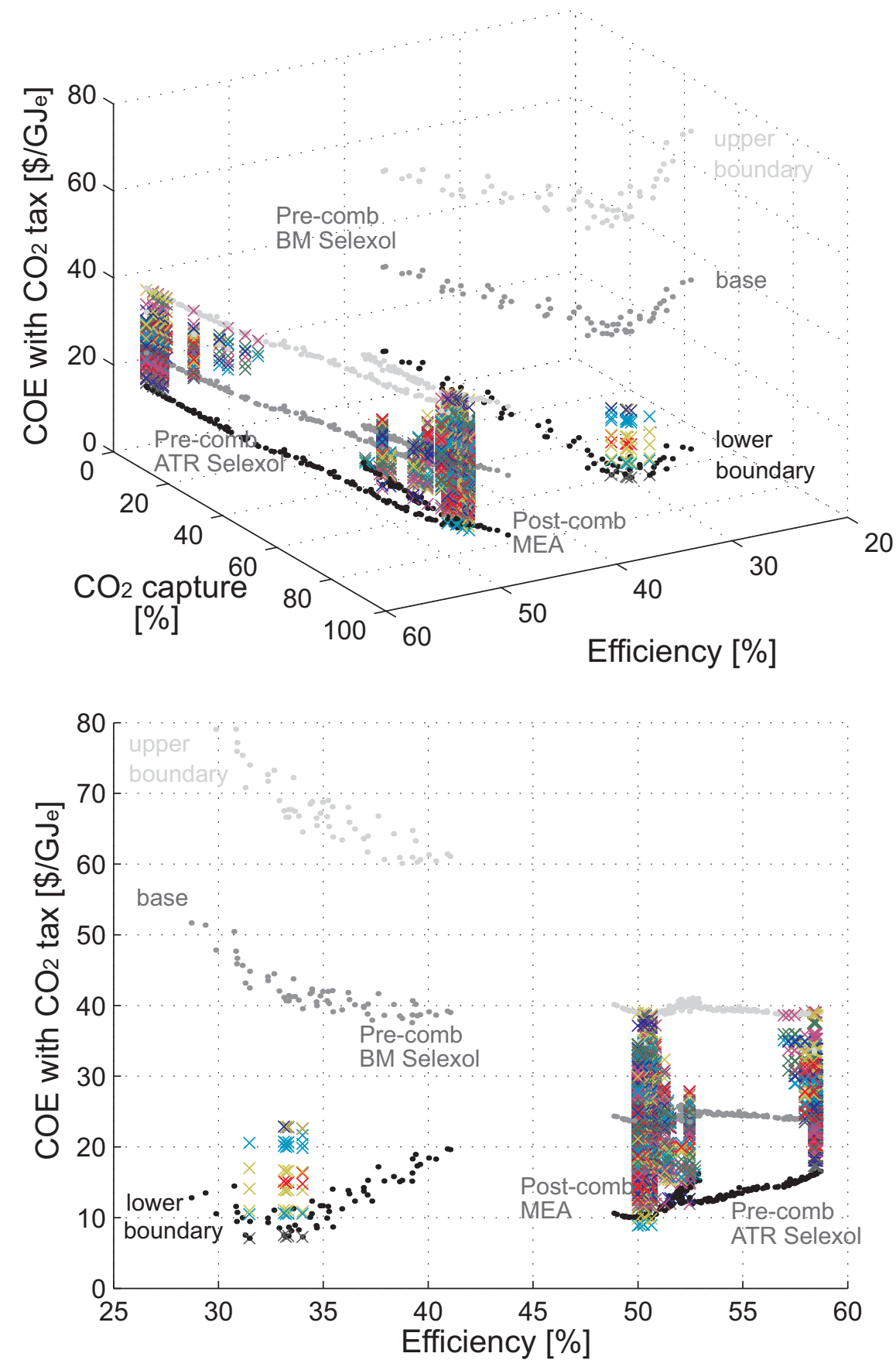

Figure 5: Power plants performance with $\mathrm{CO}_{2}$ capture: Influence of the economic scenario on the decision-making based on the top 5 configurations yielding the best economic performance. The crosses $(\mathrm{x})$ represent for each economic scenario the 5 selected configurations. Top: 3D-representation, Bottom:2D-represempation 


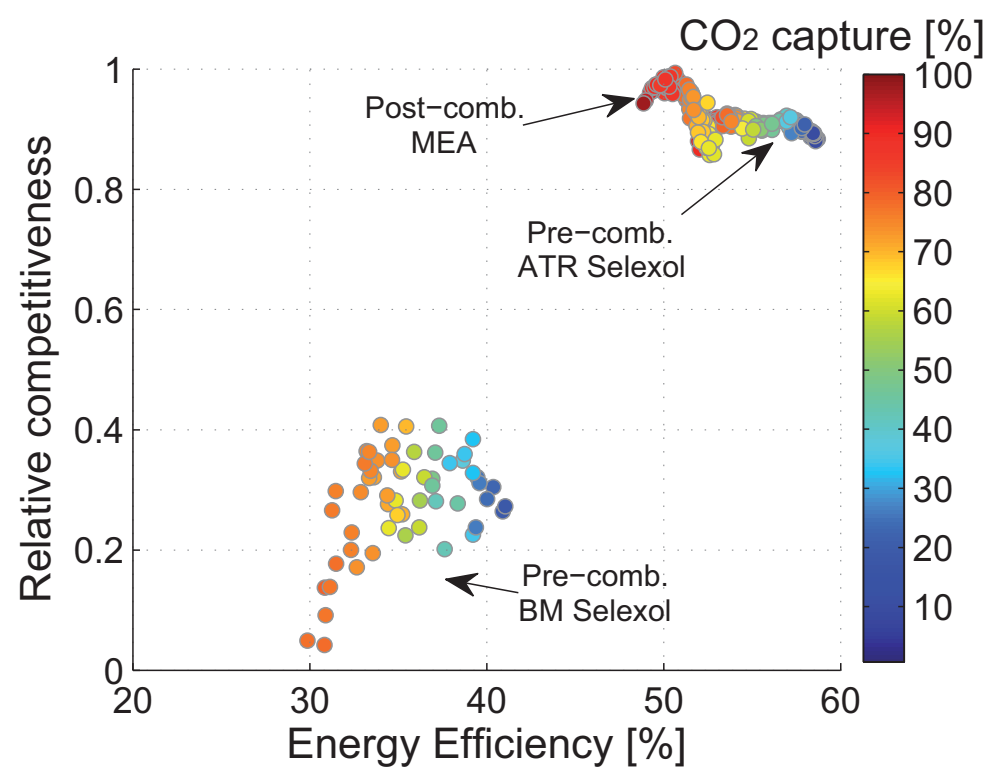

Figure 6: Relative competitiveness. 


\section{2. $S N G$ production from biomass}

The production of synthetic natural gas (SNG) from lignocellulosic biomass was investigated by Gassner et al. [16], based on the same thermo-enivironomic optimization methodology [8]. The proposed superstructure of the SNG process includes several process options for biomass drying, gasification, cleaning, $\mathrm{CO}_{2}$ removal and SNG upgrading. In [36] a database of Pareto-optimal flowsheets for all the potential combinations of candidate technologies has been generated by combining the superstructure process model with multiobjective optimisation techniques. The database consists of 118 Pareto frontiers that differ mainly by the following technology choices (illustrated in Figure 7):

- Wood drying technology: drying with hot air or steam

- Gasification technology: fast internally circulating fluidised bed (FICFB) gasifier at atmospheric pressure or pressurized ( $F F I C F B)$ and circulating fluidised bed (CFB) gasification directly heated with $\mathrm{O}_{2}$ (CFBO2).

- Gas cleaning technology: hot gas cleaning (HCL) or cold gas cleaning $(C C L)$

- Methane upgrading technology (i.e. $\mathrm{CO}_{2}$ capture): pressure swing adsorption (PSA), Selexol absorption and membrane processes. The upgrading can be performed upstream or downstream the methanation

The different Pareto frontiers are described in detail and listed in Appendix.

The influence of the economic conditions and of the plant scale were briefly discussed in [36] and the most economically plants have been identified based on the maximum biomass break even cost for different conditions. 




Figure 7: Process superstructure of the SNG production (Figure reproduced from [36]).

Since the different process designs differ in terms of the amount of electricity and heat that is consumed, respectively produced, the economic competitiveness is highly dependent on the market parameters such as the SNG, heat and electricity selling price and the biomass and electricity purchase price. To assess systematically the influence of the economic conditions and to rank the different process designs based on the probability to be part of the top performing ones the decision support approach previously described is applied here.

The analysis is performed for a plant scale of $100 \mathrm{MW}_{t h}$. It is considered that the produced SNG is used as an automotive fuel. The produced electricity is sold as 'green' electricity. The economic conditions uncertainty is assessed through the distributions functions reported in Table 6 which have been defined based based on data from [37-39]. The considered decision criteria are the SNG production costs, the resources profitability (obtained profit), and the overall ranking with regard to the 2 decision criteria (prod. cost and profitability). 
Table 6: Definition of the economic scenarios and parameters of the distribution functions for the economic assumptions.

\begin{tabular}{lcccc}
\hline & \multicolumn{4}{c}{ Distribution functions parameters } \\
& Distribution & Param. A & Param. B & Param. C \\
\hline Biomass price $\left[\$ / \mathrm{MWh}_{B M}\right]$ & Normal & $\mu=28.6$ & $\sigma=3.5$ & - \\
$\dot{E}$ price $\left[\$ / \mathrm{MWh}_{e}\right]$ & Normal & $\mu=145$ & $\sigma=15$ & - \\
$\dot{E}$ price $\left(\right.$ green $\left[\$ / \mathrm{MWh}_{e}\right]$ & Normal & $\mu=165$ & $\sigma=20$ & - \\
Distributed heat price $[\$ / \mathrm{MWh}]$ & Beta & $\mathrm{a}=5.3$ & $\mathrm{~b}=1.37$ & $\mathrm{c}=92$ \\
SNG price (automotive fuel) $\left[\$ / \mathrm{MWh}_{S N G}\right]$ & Normal & $\mu=110$ & $\sigma=20$ & - \\
Biodiesel price $[\$ / \mathrm{MWh}$ & \\
Yearly operation $[-]$ & Normal & $\mu=105$ & $\sigma=20$ & - \\
Interest rate $[\%]$ & Normal & $\mu=0.9$ & $\sigma=0.1$ & - \\
Investment cost $[\%]$ & Normal & $\mu=0.06$ & $\sigma=0.01$ & - \\
\hline
\end{tabular}

\subsubsection{Identification of best $S N G$ process designs}

For each decision criterion, the probability to be the best process design with regard to this criterion and the probability to be part of the 5 best performing process designs (top 5) is assessed over the whole range of economic scenarios.

The results illustrated in Figure 8 clearly reveal the influence of the decision criterion on the best process design. In Figure 8 all the Parteo frontiers resulting from the multi-objective optimisation maximising the SNG equivalent efficiency and minimising the specific investment cost are illustrated. The circles represent the probability of this process design to be part of the best performing ones. The diameter of the circle is scaled in accordance with the probability. The results show that several Pareto frontiers do never enclose the best performing process designs. Different solutions emerge with the decision criteria production costs and resource profitability. The best performing process designs and the corresponding probability to be the best 
one are reported in Table 7 for the different decision criteria. In terms of production costs, the process designs the lead to the lowest cost in the large range of economic scenarios belong predominately to the same Pareto corresponding to SNG production by CFB gasification with membrane cascade downstream of methanation (nb 22 - CFBO2 $31 \mathrm{hcl}$ ). With regard to the resource profitability the best configurations are the one based on CFB gasification with Selexol absorption downstream of methanation (nb 14 - CFBO2 $21 \mathrm{hcl}$ ), followed by the one with CFB gasification and membrane cascade downstream of methanation (nb 22 - CFBO2 $31 \mathrm{hcl}$ ). This reveals the competition between the different $\mathrm{CH}_{4}$ upgrading technologies and the decision criterion. The process designs with an high SNG equivalent are the ones that yield also the best economic performance even if the specific investment costs are larger than for designs with lower efficiencies, due to the profit of selling the products.

Instead of assessing the best process design only on the probability to be the best performing one with regard to a given decision criteria, the best design is now identified by the probability to be part of the top 5 performing ones (T5). In this case the selected solutions are increased as illustrated in Figure 8 and Table 8. It appears that the most economic competitive process designs for SNG production are based on CFB gasification and hot gas cleaning, and co-produce heat for district heating purposes. The different technologies for the SNG purification after methanation are in competition. When identifying the best process design with regard to the lowest production, designs with air drying (nb 10 - CFBO2 20 hcl, nb 18 - CFBO2 30 hcl) and steam drying compete (nb 14 - CFBO2 21 hcl, nb 22 - CFBO2 31 hcl) 




Figure 8: Pareto frontiers resulting from multi-objective optimisation of SNG processes [36] and identification of best process designs based on different decision criteria. The circles are proportional to the probability to be part of the best process designs.

with each other.

As the two different decision criteria can lead to the selection of different process designs, an overall ranking can also be established by combining the ranking of each process design with regard to the decision criteria. This allows to identify the most reliable process designs in a large range of economic scenarios. In this case, some SNG production processes based on FICFB gasification (no 101) become interesting as illustrated in Figure 8.

Taking into account the economic conditions uncertainty, the same approach can also be applied to identify the best process designs from one single Pareto or from a reduced number of technology scenarios from the SNG processes database (for example, only those with district heating, or only CFB 
Table 7: Identification of the 5 best process designs in terms of production costs and resource profitability and corresponding probability to be the best performing one. The designs are characterised by XX_YY where XX is the number of the Pareto (Appendix) and $\mathrm{YY}$ is the number of the design in this Pareto.

\begin{tabular}{|c|c|c|c|c|c|c|}
\hline \multicolumn{7}{|c|}{ Prod. Cost } \\
\hline $\mathrm{N}^{o}$ & Gasifier & $\begin{array}{l}\text { Design } \\
\mathrm{CO}_{2} \text { capture }\end{array}$ & Drying & $\begin{array}{l}\text { Proba. } \\
\%\end{array}$ & $\begin{array}{l}\epsilon_{S N G} \\
\%\end{array}$ & $\begin{array}{l}\text { Invest. } \\
\$ / k W\end{array}$ \\
\hline $22 \_27$ & $\mathrm{CFB} \mathrm{O}_{2}$ & Membrane & Steam & 63 & 85.4 & 818 \\
\hline 22_30 & CFB $\mathrm{O}_{2}$ & Membrane & Steam & 18.3 & 85.2 & 801 \\
\hline 22_06 & $\mathrm{CFB} \mathrm{O}_{2}$ & Membrane & Steam & 16.1 & 84.2 & 768.7 \\
\hline 74_38 & pFICFB & PSA & Air & 0.8 & 81.3 & 1418.7 \\
\hline 74_31 & $\mathrm{FB}$ & PSA & Air & 0.6 & 81 & 1611 \\
\hline \multicolumn{7}{|c|}{ Profitability } \\
\hline $\mathrm{N}^{o}$ & Gasifier & $\begin{array}{l}\text { Design } \\
\mathrm{CO}_{2} \text { capture }\end{array}$ & Drying & $\begin{array}{l}\text { Proba. } \\
\%\end{array}$ & $\begin{array}{l}\epsilon_{S N G} \\
\%\end{array}$ & $\begin{array}{l}\text { Invest. } \\
\$ / k W\end{array}$ \\
\hline $14 \_51$ & $\mathrm{CFB} \mathrm{O}_{2}$ & Selexol & Steam & 20.7 & 85.6 & 721 \\
\hline 14_32 & $\mathrm{CFB} \mathrm{O}_{2}$ & Selexol & Steam & 15.7 & 85.8 & 731 \\
\hline 22_30 & $\mathrm{CFB} \mathrm{O}_{2}$ & Membrane & Steam & 15.3 & 85.2 & 801 \\
\hline $22 \_27$ & $\mathrm{CFB} \mathrm{O}_{2}$ & Membrane & 12.9 & Steam & 85.4 & 818 \\
\hline 14_69 & $\mathrm{CFB} \mathrm{O}_{2}$ & Selexol & Steam & 12.0 & 85.8 & 735 \\
\hline
\end{tabular}

with steam drying,...).

\section{Conclusions}

This paper presents a decision support approach that takes into account the variability of the economic conditions to identify the most economically competitive process designs from a multi-objective optimisation Pareto set. The approach is applied to systematically assess $\mathrm{CO}_{2}$ capture options in power production processes and SNG-fuel production processes. The competition between the different process designs and the decision criteria is pointed out and the influence of the economic conditions on the decision-making is highlighted.

For $\mathrm{CO}_{2}$ capture processes the optimal power plant design is highly in- 
Table 8: Identification of the 10 best process designs in terms of production costs and resource profitability and corresponding probability to be part of the 5 best performing process designs. The designs are characterised by XX_YY where $\mathrm{XX}$ is the number of the Pareto (Appendix) and YY is the number of the design in this Pareto.

\begin{tabular}{|c|c|c|c|c|c|c|}
\hline \multicolumn{7}{|c|}{ Prod. Cost } \\
\hline $\mathrm{N}^{o}$ & Gasifier & $\begin{array}{c}\text { Design } \\
\mathrm{CO}_{2} \text { capture }\end{array}$ & Drying & $\begin{array}{l}\text { Proba. } \\
\%\end{array}$ & $\begin{array}{l}\epsilon_{S N G} \\
\%\end{array}$ & $\begin{array}{l}\text { Invest. } \\
\$ / k W\end{array}$ \\
\hline 18_62 & $\mathrm{CFB} \mathrm{O}_{2}$ & Membrane & Air & 18.4 & 81.1 & 879 \\
\hline 10_60 & $\mathrm{CFB} \mathrm{O}_{2}$ & Selexol & Air & 15.5 & 81.1 & 755 \\
\hline 21_37 & $\mathrm{CFB} \mathrm{O}_{2}$ & Membrane & Steam (CGCL) & 14.1 & 80.4 & 787 \\
\hline $22 \_27$ & $\mathrm{CFB} \mathrm{O}_{2}$ & Membrane & Steam & 12.9 & 85.4 & 818 \\
\hline 14_69 & $\mathrm{CFB} \mathrm{O}_{2}$ & Selexol & Steam & 8.6 & 85.9 & 736 \\
\hline 14_51 & $\mathrm{CFB} \mathrm{O}_{2}$ & Selexol & Steam & 6.0 & 85.6 & 721 \\
\hline 22_30 & $\mathrm{CFB} \mathrm{O}_{2}$ & Membrane & Steam & 3.7 & 85.2 & 801 \\
\hline 14_15 & $\mathrm{CFB} \mathrm{O}_{2}$ & Selexol & Steam & 3.7 & 84.6 & 708 \\
\hline 22_06 & $\mathrm{CFB} \mathrm{O}_{2}$ & Membrane & Steam & 3.2 & 84.2 & 769 \\
\hline 21_63 & $\mathrm{CFB} \mathrm{O}_{2}$ & Membrane & Steam (CGCL) & 2.9 & 79.2 & 751 \\
\hline \multicolumn{7}{|c|}{ Profitability } \\
\hline $\mathrm{N}^{o}$ & Gasifier & $\begin{array}{c}\text { Design } \\
\mathrm{CO}_{2} \text { capture }\end{array}$ & Drying & $\begin{array}{l}\text { Proba. } \\
\%\end{array}$ & $\begin{array}{l}\epsilon_{S N G} \\
\%\end{array}$ & $\begin{array}{l}\text { Invest. } \\
\$ / k W\end{array}$ \\
\hline $22 \_30$ & $\mathrm{CFB} \mathrm{O}_{2}$ & Membrane & Steam & 11.7 & 85.2 & 801 \\
\hline $10 \_60$ & $\mathrm{CFB} \mathrm{O}_{2}$ & Selexol & Air & 11.2 & 81.1 & 755 \\
\hline $6 \_50$ & $\mathrm{CFB} \mathrm{O}_{2}$ & PSA & Steam & 9.8 & 85.1 & 860 \\
\hline 14_51 & $\mathrm{CFB} \mathrm{O}_{2}$ & Selexol & Steam & 7.8 & 85.6 & 721 \\
\hline 14_69 & $\mathrm{CFB} \mathrm{O}_{2}$ & Selexol & Steam & 5.2 & 85.9 & 736 \\
\hline $22 \_27$ & $\mathrm{CFB} \mathrm{O}_{2}$ & Membrane & Steam & 4.3 & 85.4 & 818 \\
\hline 18_62 & $\mathrm{CFB} \mathrm{O}_{2}$ & Membrane & Air & 4.3 & 81.1 & 879 \\
\hline 31_51 & $\mathrm{CFB} \mathrm{O}_{2}$ & Membrane & Steam (CGCL) & 4.2 & 81.7 & 698 \\
\hline 14_32 & $\mathrm{CFB} \mathrm{O}_{2}$ & Selexol & Steam & 3.2 & 85.8 & 732 \\
\hline 22_06 & $\mathrm{CFB} \mathrm{O}_{2}$ & Membrane & Steam & 3.0 & 84.2 & 769 \\
\hline
\end{tabular}

fluenced by the resource price and the introduction of a carbon tax. It is determined by the production scope and the priorities given to the different thermo-environomic criteria. By including the economic conditions sensitivity in the decision-making step, it appears that apart from the economic market conditions, the $\mathrm{CO}_{2}$ capture rate is a key factor defining the economic competitiveness. Post-combustion $\mathrm{CO}_{2}$ capture reveals to be economically 
competitive for capture rates between 70 and $80 \%$ when a carbon tax is introduced. This contradicts the rates up to $95 \% \mathrm{CO}_{2}$ capture that are typically recommended. It is shown that for specific economic conditions (i.e. introduction of a carbon tax) CCS can become an energy, cost and environmental efficient alternative on the future energy market when compared to a conventional NGCC plant.

For the polygeneration of SNG, heat and power from biomass, it is revealed that the most economically competitive process design is highly influenced by the gasifier and the methane upgrading technology. In figure 8 one can see that, considering the uncertainty analysis, the most probable best solutions lies in the right of the Pareto curve. This part of the Pareto corresponds to high efficiency (one of the objective function that is optimized) and as well high investment. This shows that for the selected economic solutions, it is important to promote the development of efficient processes even if those are more expensive. This can be explained by the benefit of selling the coproduced heat and power that adds to the produced SNG-fuel and that compensate the increase of the investment.

The use of the uncertainty analysis method is a powerful tool to help in the identification of the best process designs by highlighting the designs that have the highest probability of being the best considering the variability of the economic conditions. Such a tool is therefore an important tool to generate a limited list of configurations to be compared. 


\section{References}

[1] ZEP . The costs of CO2 capture, transport and storage - Post-demonstration CCS in the EU. Report; European Technology Platform; Brussels, Belgium; 2011. URL http://www .zeroemissionsplatform.eu/library.html.

[2] Finkenrath M. Cost and performance of carbon dioxide capture from power generation. Report; International Energy Agency; Paris, France; 2011.

[3] Basson L, Petrie J. A critical systems approach to decision support for process engineering. Computers \& Chemical Engineering 2007;31(8):876 -88 .

[4] Bortz M, Burger J, Asprion N, Blagov S, Bttcher R, Nowak U, et al. Multi-criteria optimization in chemical process design and decision support by navigation on pareto sets. Computers \& Chemical Engineering $2014 ; 60(0): 354-63$.

[5] Burger J, Asprion N, Blagov S, Böttcher R, Nowak U, Bortz M, et al. Multi-objective optimization and decision support in process engineering-implementation and application. Chemie Ingenieur Technik 2014;86(7):1065-72.

[6] $\mathrm{Hu} \mathrm{M}$, Cho H. A probability constrained multi-objective optimization model for $\{\mathrm{CCHP}\}$ system operation decision support. Applied Energy 2014;116(0):230 -42. 
[7] Gaspar Cunha A, Ferreira J, Covas J, Recio G. Selection of solutions in multi-objective optimization: Decision making and robustness. In: Computational Intelligence in Multi-Criteria Decision-Making (MCDM), 2014 IEEE Symposium on. 2014,.

[8] Gerber L, Gassner M, Maréchal F. Systematic integration of LCA in process systems design: Application to combined fuel and electricity production from lignocellulosic biomass. Computers \& Chemical Engineering 2011;35:1265 -80.

[9] Tock L, Maréchal F. Platform development for studying integrated energy conversion processes: Application to a power plant process with CO2 capture. Computer-aided Chemical Engineering 2012;31:1015-9.

[10] IEA . Key World Energy Statistics. Report; International Energy Agency; Paris, France; 2012.

[11] IEA . Medium-term Oil \& Gas Markets. Report; International Energy Agency; Paris, France; 2011.

[12] European Commission . EU energy trends to 2030 - Update 2009. Report; European Commission; 2010.

[13] Eurostat . . European Commission. http://epp.eurostat.ec.europa.eu/portal/page/portal/eurostat/home; last visited 20/05/2014.

[14] EU . Energy roadmap 2050. Communication from the Commission to the Council, the European Parliament, the European Economic and 
Social Committee and the Committee of Regions. SEC(2011) 1565/2;

European Commission; Luxembourg; 2011.

[15] European Commission . The state of the european carbon market in 2012. Report from the Commission to the European Parliament and the council COM(2012) 652; European Commission; 2012.

[16] Gassner M, Maréchal F. Methodology for the optimal thermo-economic, multi-objective design of thermochemical fuel production from biomass. Computers \& Chemical Engineering 2009;33:769-81.

[17] Maréchal F, Kalitventzeff B. Process integration: Selection of the optimal utility system. Computers \& Chemical Engineering 1998;22:149-56.

[18] Turton R. Analysis, Synthesis, and Design of Chemical Processes. Upper Saddle River, N.J, United States: Prentice Hall; 3rd ed ed.; 2009.

[19] Ulrich G, Vasudevan P. A Guide to Chemical Engineering Process Design and Economics a Practical Guide. Boca Raton, Fla, United States: CRC; 2nd ed ed.; 2003.

[20] Molyneaux A, Leyland G, Favrat D. Environomic multi-objective optimisation of a district heating network considering centralized and decentralized heat pumps. Energy 2010;35(2):751-8.

[21] Brown TR, Wright MM. Techno-economic impacts of shale gas on cellulosic biofuel pathways. Fuel 2014;117, Part B(0):989 -95.

[22] Metz B, Davidson O, de Coninck H, Loos M, Meyer L. IPCC special 
report on carbon dioxide capture and storage. Report; Cambridge University Press; Cambridge, England; 2005.

[23] Meerman J, Hamborg E, van Keulen T, Ramírez A, Turkenburg W, Faaij A. Techno-economic assessment of $\mathrm{CO} 2$ capture at steam methane reforming facilities using commercially available technology. International Journal of Greenhouse Gas Control 2012;9(0):160-71.

[24] Kanniche M, Gros-Bonnivard R, Jaud P, Valle-Marcos J, Amann J, Bouallou C. Pre-combustion, post-combustion and oxy-combustion in thermal power plant for $\mathrm{CO} 2$ capture. Applied Thermal Engineering 2010;30(1):53-62.

[25] Cormos CC, Padurean A, Agachi PS. Technical evaluations of carbon capture options for power generation from coal and biomass based on integrated gasification combined cycle scheme. Energy Procedia 2011;4(0):1861-8.

[26] Berstad D, Arasto A, Jordal K, Haugen G. Parametric study and benchmarking of NGCC, coal and biomass power cycles integrated with MEAbased post-combustion CO2 capture. Energy Procedia 2011;4(0):173744.

[27] Romano MC, Chiesa P, Lozza G. Pre-combustion CO2 capture from natural gas power plants, with ATR and MDEA processes. International Journal of Greenhouse Gas Control 2010;4(5):785-97.

[28] Kvamsdal HM, Jordal K, Bolland O. A quantitative comparison of gas turbine cycles with CO2 capture. Energy 2007;32(1):10-24. 
[29] Singh B, Strømman AH, Hertwich E. Life cycle assessment of natural gas combined cycle power plant with post-combustion carbon capture, transport and storage. International Journal of Greenhouse Gas Control 2011;5(3):457-66.

[30] Viebahn P, Nitsch J, Fischedick M, Esken A, Schüwer D, Supersberger $\mathrm{N}$, et al. Comparison of carbon capture and storage with renewable energy technologies regarding structural, economic, and ecological aspects in Germany. International Journal of Greenhouse Gas Control 2007;1(1):121-33.

[31] Abu-Zahra MR, Niederer JP, Feron PH, Versteeg GF. CO2 capture from power plants: Part II. A parametric study of the economical performance based on mono-ethanolamine. International Journal of Greenhouse Gas Control 2007;1(2):135-42.

[32] Tock L, Maréchal F. Process design optimization strategy to develop energy and cost correlations of co2 capture processes. Computers \& Chemical Engineering 2014;61(0):51 -8.

[33] Tock L, Maréchal F. H2 processes with CO2 mitigation: Thermoeconomic modeling and process integration. International Journal of Hydrogen Energy 2012;37:11785-95.

[34] Tock L, Maréchal F. CO2 mitigation in thermo-chemical hydrogen processes: Thermo-environomic comparison and optimization. Energy Procedia 2012;29(0):624-32. 
[35] Tock L, Maréchal F. Co-production of hydrogen and electricity from lignocellulosic biomass: Process design and thermo-economic optimization. Energy 2012;45:339-49.

[36] Gassner M, Marechal F. Thermo-economic optimisation of the polygeneration of synthetic natural gas (sng), power and heat from lignocellulosic biomass by gasification and methanation. Energy and Environmental Science 2012;5:5768-89.

[37] WVS . Swiss forest owners association, Energy wood price statistics. http://www.wvs.ch/en/home.html ; last visited 20/05/2014.

[38] ElCom . Swiss Federal Electricity Comission ElCom, Electricity price overview. http://www.elcom.admin.ch/?lang=en; last visited $20 / 05 / 2014$.

[39] NGVA Europe . Natural \& bio Gas Vehicle Association, European NGVA statistics. http://www.ngvaeurope.eu/european-ngv-statistics ; last visited 20/05/2014. 


\section{Appendix}

SNG production process options

The database of the Pareto-optimal SNG processes' flowsheets was generated in [36]. The database consist of 118 Pareto fronts listed here below. The technology scenarios names are labeled according the following abbreviations.

- FICFB: FICFB gasification at atmospheric pressure

- pFICFB: pressurised FICFB gasification

- pFICFBgt: pressurised FICFB gasification with power recovery by expanding the flue gases in turbine

- CFBO2: pressurised CFB gasification directly heated with oxygen

- XXY: X: CO2-removal technology (X=BN_CO2REM; 1/4: PSA downstream/upstream of methanation; 2/5: Selexol absorption downstream/upstream of methanation; 3: membrane cascade downstream methanation) Y: drying technology (Y=BN_DRY-1; 0: air drying, 1: steam drying)

- _tor: with torrefaction (i.e. BN_PYR=4, otherwise BN_PYR=0)

- _hcl: hot gas cleaning (i.e. BN_GCL=2, otherwise cold gas cleaning $(\mathrm{BN}-\mathrm{GCL}=1))$

- _nodh: without district heating (i.e. $\mathrm{BN} \_\mathrm{DH}=0$, otherwise with heat cogeneration into a $110 / 70^{\circ} \mathrm{C}$ distribution grid $\left.\left(\mathrm{BN} \_\mathrm{DH}=1\right)\right)$

Numbered list of all the technology scenarios considered for the SNG production: 

1. $\mathrm{CFBO}_{-} \_10$
2. CFBO2_10_hcl
3. CFBO2_10_hcl_nodh
4. CFBO2_10_nodh
5. CFBO2_11
6. CFBO2_11_hcl
7. CFBO2_11_hcl_nodh
8. CFBO2_11_nodh
9. CFBO2 $\_20$
10. CFBO2_20_hcl
11. CFBO2_20_hcl_nodh
12. CFBO2_20_nodh
13. CFBO2_21
14. CFBO2_21_hcl
15. CFBO2_21_hcl_nodh
16. CFBO2_21_nodh
17. CFBO2_30
18. CFBO2_30_hcl
19. CFBO2_30_hcl_nodh
20. CFBO2_30_nodh
21. CFBO2_31
22. CFBO2_31_hcl
23. CFBO2_31_hcl_nodh
24. CFBO2_31_nodh
25. CFBO2_40
26. CFBO2_40_nodh
27. CFBO2_41
28. CFBO2_41_nodh
29. CFBO2_50
30. CFBO2_50_nodh
31. CFBO2_51
32. CFBO2_51_nodh
33. FICFB_10
34. FICFB_10_nodh
35. FICFB_10_tor
36. FICFB_10_tor_nodh
37. FICFB_11
38. FICFB_11_nodh
39. FICFB_11_tor
40. FICFB_11_tor_nodh

41. FICFB_20

42. FICFB_20_nodh

43. FICFB_20_tor

44. FICFB_20_tor_nodh

45. FICFB_21

46. FICFB_21_nodh

47. FICFB_21_tor

48. FICFB_21_tor_nodh

49. FICFB_30

50. FICFB_30_nodh

51. FICFB_30_tor

52. FICFB_30_tor_nodh

53. FICFB_31

54. FICFB_31_nodh

55. FICFB_31_tor

56. FICFB_31_tor_nodh

57. FICFB_40

58. FICFB_40_nodh

59. FICFB_40_tor

60. FICFB_40_tor_nodh

61. FICFB_41

62. FICFB_41_nodh

63. FICFB_41_tor

64. FICFB_41_tor_nodh

65. FICFB_50

66. FICFB_50_nodh

67. FICFB_50_tor

68. FICFB_50_tor_nodh

69. FICFB_51

70. FICFB_51_nodh

71. FICFB_51_tor

72. FICFB_51_tor_nodh

73. pFICFB_10

74. pFICFB_10_hcl

75. pFICFB_10_hcl_nodh

76. pFICFB_10_nodh

77. pFICFB_11

78. pFICFB_11_hcl

79. pFICFB_11_hcl_nodh

80. pFICFB_11_nodh
81. pFICFB_20

82. pFICFB_20_hcl

83. pFICFB_20_hcl_nodh

84. pFICFB_20_nodh

85. pFICFB_21

86. pFICFB_21_hcl

87. pFICFB_21_hcl_nodh

88. pFICFB_21_nodh

89. pFICFB_30

90. pFICFB_30_hcl

91. pFICFB_30_hcl_nodh

92. pFICFB_30_nodh

93. pFICFB_31

94. pFICFB_31_hcl

95. pFICFB_31_hcl_nodh

96. pFICFB_31_nodh

97. pFICFBgt_10

98. pFICFBgt_10_hcl_nodh

99. pFICFBgt_10_nodh

100. pFICFBgt_11

101. pFICFBgt_11_hcl

102. pFICFBgt_11_hcl_nodh

103. pFICFBgt_11_nodh

104. pFICFBgt_20

105. pFICFBgt_20_hcl

106. pFICFBgt_20_hcl_nodh

107. pFICFBgt_20_nodh

108. pFICFBgt_21

109. pFICFBgt_21_hcl

110. pFICFBgt_21_hcl_nodh

111. pFICFBgt_21_nodh

112. pFICFBgt_30

113. pFICFBgt_30_hcl

114. pFICFBgt_30_hcl_nodh

115. pFICFBgt_30_nodh

116. pFICFBgt_31

117. pFICFBgt_31_hcl_nodh

118. pFICFBgt_31_nodh 